\title{
El Recurso de Homologación y su origen en relación al Derecho de Arbitramiento consagrado en el artículo 139 de la Constitución de la República
}

Ramón Ortez Abadie

Profesor Docente, Facultad de Ciencias Jurídicas

Universidad Nacional Autónoma de Honduras

\section{RESUMEN}

La Constitución de la República de Honduras consagra en su artículo 139 el Derecho del Arbitramiento bajo los efectos de su regulación jurídica. Con énfasis especial en el Derecho Laboral y bajo una historia de conflictos laborales producto de los procesos sindicales históricos, se plantea en el siguiente artículo como y de qué forma se logran integrar estos conceptos en la Legislación misma que recurre al órgano jurisdiccional competente con carácter voluntario y con el objetivo de Homologar la resolución adoptada la cual no es ajena a un procedimiento jurídico expedito y efectivo.

\section{ABSTRACT}

The Constitution of the Republic of Honduras establishes under the influence of its legal regulation the right of Arbitration, contained in Article 139. With special emphasis on labor law and under history of labor disputes, product of historical union processes, the following article shows how these concepts are integrated in the legislation itself, that turns to the competent court on a voluntary basis and in order to homologate the taken decision that is no longer alien to a legal expeditious and effective proceeding.

Palabras clave: Derecho de Homo- Keywords: Right of Approval, Labor, logación. Laboral, Constitución Hon- 1982 Honduras Constitution, Voluntary duras 1982, Carácter Voluntario, Arbi- character, Arbitration. Art 139. tramiento, Art. 139. 


\section{CAPÍTULO I}

\section{FUNDAMENTO DEL DERECHO CONSTITUCIONAL DEL ARBITRAMIENTO}

\section{EL ARTíCULO 139 COMO REGULADOR DEL DERECHO DE ARBITRAMIENTO CONSAGRADO EN LA CONSTITUCIÓN DE LA REPÚBLICA.}

Previo a entrar a lo que es en sí la descripción del recurso de Homologación que se interpone ante el o los árbitros, para sustanciarlo ante la Honorable Corte Suprema de Justicia, debemos entender de una manera general lo que es su causa, ya que este recurso es un efecto del arbitramiento voluntario, y este a su vez encuentra su fundamento en el artículo 139 de la Constitución que literalmente dice: "El Estado tiene la obligación de promover, organizar y regular la conciliación y el arbitraje para la solución pacifica de los conflictos de trabajo".

Este fundamento deja claramente establecida la obligación que tiene el Estado de promover, organizar y regular y a su vez el Derecho que concede el mismo para la solución pacifica de los conflictos laborales entre patronos y trabajadores utilizando los métodos necesarios para alcanzar la conciliación de las diferencias, o de ser necesario Ilegar al arbitraje, con árbitros, nominados por ellos, ahora bien, esto desemboca en el recurso de homologación, como lo explicaremos más explícitamente adelante, cuando una o ambas de las partes no están conformes con el laudo (resolución) que emite el arbitro; y allí mismo ante sus oficios, interponen el Recurso de Homologación ante la Honorable Corte Suprema de Justicia, que resolverá el desacuerdo, como también explicaremos más adelante.

\section{ACERCA DEL ARBITRAMIENTO.}

Según el CÓDIGO DEL TRABAJO, en su CAPITULO XIII referente a los PROCEDIMIENTOS EN LA RESOLUCIÓN DE LOS CONFLICTOS COLECTIVOS DE CARÁCTER ECONÓMICO SOCIAL; luego de regular el arreglo directo y la conciliación; en su sección $V$ regula el Procedimiento de ARBITRAJE, comenzando por el Arbitramiento Voluntario, que el artículo 807 del Código del trabajo regula de la siguiente manera "Los patronos y los trabajadores podrán estipular que las controversias que surjan entre ellos por razón de sus relaciones de trabajo sean dirimidas por arbitradores". 
Como se desprende del artículo arriba enunciado el arbitramiento entre patronos y trabajadores se produce por el acuerdo entre ambos, mediante arbitradores. Para efectos de establecer cómo se designan los árbitros el artículo 809, se refieren a la Designación de Árbitros, de la siguiente manera: "Las partes podrán designar uno (1) o varios árbitros, como a bien lo tengan, y comprometer en corporaciones nacionales de cualquier clase".

Si las partes no hubieren acordado la manera de hacer la designación, cada una de ellas nombrará un árbitro, y éstos, como primera providencia, designarán un tercero que con ello integre el Tribunal. Si los dos árbitros escogidos por las partes no se pusieren de acuerdo en el término de veinticuatro (24) horas, será tercero el respectivo Inspector de Trabajo y, en su defecto, el Alcalde del lugar. Si la parte obligada a nombrar árbitro no lo hiciere o se mostrare renuente, el Juez de Trabajo del Lugar, previo requerimiento de tres (3) días, procederá a designarlo".

De la declaración que hace este artículo encontramos las siguientes formas de designar uno o más árbitros por las partes:

1. Nombrar uno o más árbitros de mutuo acuerdo.

2. Cada parte nombra su árbitro y éstos un tercero para integrar un tribunal que en caso de no haber acuerdo puede ser un inspector del trabajo o el alcalde del lugar.

3. La designación del árbitro de la parte renuente la puede hacer el Juez del Trabajo del Lugar.

El Artículo 810 nos habla por su parte sobre el Reemplazo de Árbitros, de la siguiente manera: "En caso de falta de impedimento de alguno de los árbitros se procederá a reemplazarlo en la misma forma en que se hizo la designación. Si una de las partes se mostrare renuente a reemplazar al árbitro que le corresponde, los dos restantes, previo requerimiento a la parte renuente con un término de tres (3) días, procederán hacer tal designación".

A continuación se procede a la Audiencia, que consiste en lo siguiente: "Artículo 811. El árbitro o los árbitros señalarán día y hora para oír a las partes, examinar los testigos que presenten, enterarse de los documentos que exhiban y de las razones que aleguen". 
Aquí se toman testigos por los árbitros, se reciben los documentos que cada parte estime pertinentes y se escuchan las razones de las partes, todo con el objetivo de formularse el árbitro un criterio acerca del conflicto que es sometido a su consideración. Una vez evacuada esta audiencia el Código del Trabajo concede a los árbitros lo que se denomina Término para fallar; el que establece de la siguiente manera: “Artículo 812. Los árbitros proferirán el fallo dentro del término de diez (10) días, contados desde la integración del Tribunal. Las partes podrán ampliar este plazo". Como resulta del texto del mismo artículo el plazo es flexible y su duración dependerá únicamente del acuerdo entre las partes, que lo pueden ampliar a su criterio y acuerdo mutuo. Cuando las partes hayan fijado un término para fallar, se debe dar este fallo que se conoce con el nombre de "Laudo" de la forma siguiente Forma del Fallo. "Artículo 813. El laudo se extenderá a continuación de lo actuado y deberá acomodarse en lo posible a las sentencias que dicten los jueces en los Juicios del Trabajo".

Del Texto del artículo se desprende que él o los árbitros deben dictar su laudo arreglado a derecho, conteniendo en lo posible todas las formalidades legales, que se ajusten al derecho sustantivo vigente, que rija en materia del trabajo, con sujeción a las reglas de la sana crítica y no sujeto a la tarifa legal de la prueba tal y como lo expresa el Código del Trabajo Vigente. (En el anexo del presente trabajo investigativo se agrega un laudo). Con respecto a los Honorarios y Gastos, el Código del Trabajo deja establecido lo siguiente: "Artículo 814. Los honorarios y gastos del Tribunal se pagarán por partes iguales, salvo que los interesados acuerden otra forma de pago".

Una vez establecido lo anterior lo pertinente a los Honorarios y Gastos de los árbitros es menester dejar establecido en el siguiente artículo: Artículo 816 "El Fallo arbitral se notificará personalmente a las partes, hará tránsito de cosa juzgada y solo será susceptible del recurso de homologación de que trata el artículo siguiente".

Como vemos, del artículo anterior se establece que el laudo arbitral tiene carácter vinculante y es susceptible únicamente, para efecto de su enmienda o revisión del recurso de Homologación, lo que nos hace entrar en la materia del presente trabajo investigativo y que pasaremos a desarrollar en el siguiente capítulo de nuestra investigación. 


\section{CAPÍTULO II}

\section{CONCEPTO GENERAL, FINALIDAD Y NATURALEZA JURÍDICA DE LA HOMOLOGACIÓN}

\section{CONCEPTO GENERAL Y FINALIDAD DEL RECURSO DE HOMOLOGACIÓN}

Según el diccionario jurídico elemental de Cabanellas, primero se define Homologar como: "Dar a las partes firmeza de cosa juzgada al fallo de los árbitros. Auto o providencia del Juez que confirma actos o contratos de las partes. A fin de hacerlos más firmes ejecutivos y solemnes"; y propiamente Homologación, como: "Aprobación, consentimiento, ratificación. Confirmación Judicial de determinados actos de las partes, para la debida constancia y eficacia, firmeza que el laudo arbitral concede al transcurso del término legal sin impugnar el fallo de los árbitros".

En Honduras encontramos que el Recurso de Homologación se convierte en el último recurso procesal que tienen las partes que se han sometido al arbitramiento, contra el laudo que los árbitros emiten. Según el Código del Trabajo encontramos que se establece para el Recurso de Homologación, la siguiente disposición: Artículo 817 "Establecese un recurso extraordinario de homologación ante la Corte Suprema de Justicia contra los laudos arbítrales de que tratan los artículos anteriores". Y su finalidad se define claramente en el segundo párrafo del artículo subsiguiente, que dice: "Artículo 818. Si el laudo se ajustare a los términos del compromiso o de las cláusulas compromisorias y no afectare derechos o facultades reconocidas por la Constitución, por las leyes o por las normas convencionales a cualquiera de las partes, la Corte lo homologará. En caso contrario, lo anulará y dictará la resolución que lo reemplace. Contra estas decisiones de la Corte no habrá recurso alguno".

Existe asimismo un Recurso de Homologación de Laudos,_regulado en el artículo 819 del Código del Trabajo que se refiere a: "Los laudos que profieran las Juntas de Arbitraje o los Tribunales Especiales de Arbitramento., Cuando el Arbitraje fuere de carácter obligatorio. (Establecido en las cláusulas de los contratos colectivos de trabajo). Será remitido con todos sus antecedentes a la Corte Suprema de Justicia para su homologación a solicitud de una de las partes o de ambas, presentada dentro de los tres (3) días, verificará la regularidad del laudo y 
lo declarará exequible, confiriéndole fuerza de sentencia si la Junta o Tribunal de Arbitramento no hubiere extralimitado el objeto para el cual se le convocó, o lo anulará en caso contrario.

Si la Corte hallare que no se decidieron algunas de las cuestiones indicadas en el decreto de convocatoria, devolverá el expediente a los árbitros, con el fin de que se pronuncien sobre ellas, señalándoles plazo al efecto, sin perjuicio de que ordene, si lo estima conveniente la homologación de lo ya decidido. De los artículos arriba indicados se establece que los Recursos de Homologación, tienen las siguientes finalidades que son:

a. Si una vez revisado el laudo por el Tribunal Supremo, éste se ajusta a los términos del compromiso o de las cláusulas compromisorias y no afectare derechos o facultades reconocidos por la Constitución, por las leyes o normas convencionales de las partes. O sea que el LAUDO se encuentre arreglado a derecho y dictado de conformidad a todos los preceptos arriba enunciados LA CORTE LO HOMOLOGA, como lo deja establecido Cabanellas en su diccionario jurídico es la "ratificación, Confirmación Judicial de determinados actos de las partes (en este caso de los árbitros)".

b. Si la Corte hallare que no se decidieron algunas de las cuestiones indicadas en el decreto de convocatoria, devolverá el expediente a los árbitros, con el fin de que se pronuncien sobre ellas, señalándoles plazo al efecto, sin perjuicio de que ordene, si lo estima conveniente, la homologación de lo ya decidido.

\section{NATURALEZA JURÍDICA DEL RECURSO}

El Recurso de Homologación viene a constituirse como el único medio jurídico de protección y tutela que ofrece el derecho adjetivo en materia laboral para que las partes obtengan una apreciación jurídica del Tribunal Supremo en el asunto objetivo del arbitramiento, en su única instancia superior.

Todas las constituciones modernas poseen un apartado especial dedicado a la proclamación de los derechos a la conciliación y el arbitraje para la solución pacífica de los conflictos de trabajo. Nuestra constitución lo regula en el capítulo $\mathrm{V}$, en lo referente al trabajo, en su artículo 139, y por ese solo hecho se les reconoce como derechos constitucionales y su violación o inobservancia por la autoridad pública o institución de derecho privado, 
patrono o trabajador implica violación de la constitución. Y se garantiza, en el ordenamiento jurídico que regula la materia laboral en este país, como un derecho adjetivo el Recurso de Homologación ante la Honorable Corte Suprema de Justicia, contra el laudo que emitan los árbitros y se reconoce como recurso en el artículo 740 del Código del Trabajo que a la letra dice: "Artículo 740. Contra las resoluciones judiciales del trabajo procederán los siguientes recursos: 1. El de Reposición. 2. El de Apelación. 3. El de Casación. 4. El de Hecho. También procederá el Recurso Especial de Homologación en los casos previstos en este Código".

\section{CAPÍTULO III}

\section{EL RECURSO DE HOMOLOGACIÓN EN EL DERECHO HONDUREÑO}

\section{LA COMPETENCIA}

El Estado realiza sus fines a través de tres funciones jurídicamente distintas: Legislativa, Ejecutiva y Judicial o Jurisdiccional, la cuales pueden determinarse desde el punto de vista material y formal. Obviamente, para la eficacia legal de un acto o resolución de cualquier órgano estatal, es requisito indispensable, que lo realice dentro de la esfera de sus atribuciones, que esté dentro de su competencia legal, so pena de nulidad y acarreando responsabilidad.

En materia jurisdiccional el artículo 137 de la Ley de Organización y Atribuciones de los Tribunales, establece que: "La competencia es la facultad que tiene cada juez o tribunal para conocer de los negocios que las leyes han colocado dentro de la esfera de sus atribuciones".

La competencia para el conocimiento del Recurso de Homologación, la tiene exclusivamente la Corte Suprema de Justicia, según se desprende del artículo 817 del Código del Trabajo que dice en lo conducente Artículo 817. "Establece un Recurso Extraordinario de Homologación ante la Corte Suprema de Justicia contra los laudos arbítrales de que tratan los artículos anteriores". 
Aún y cuando el arbitramiento es un procedimiento administrativo que se puede desarrollar entre patronos y trabajadores en todo el país, el Recurso de homologación, únicamente puede ser conocido por la Corte Suprema de Justicia.

\section{REQUISITOS BÁSICOS DE LA HOMOLOGACIÓN}

Los requisitos básicos para que pueda admitirse en primera instancia el recurso de Homologación se desprenden del artículo 817 del Código del Trabajo vigente y son los siguientes:

a. Establece el recurso extraordinario de homologación que se interpone ante la Corte Suprema de Justicia.

b. Que es contra los laudos arbítrales que trata el Código del Trabajo.

c.- Y que este recurso deberá interponerse por cualquiera de las partes (que participen en el arbitraje).

\section{TRÁMITE DE HOMOLOGACIÓN EN EL ARBITRAJE VOLUNTARIO Y OBLIGATORIO}

De los requisitos arriba enunciados se desprende el trámite que debe seguirse para interponer el recurso de homologación, el mismo está contenido en los artículos 817, 818 y 819 del Código del trabajo y el mismo es el siguiente:

\section{a. Recurso de homologación en el arbitraje voluntario:}

1. Este recurso deberá interponerse por cualquiera de las partes que participen en el arbitraje.

2. Ante el o los árbitros, dentro de los tres (3) días siguientes a la notificación.

3. El proceso, deberá ser remitido por el o los árbitros, a la Corte Suprema de Justicia, dentro de los dos (2) días siguientes a su interposición.

4. Recibido el expediente por la Corte y efectuado el reparto, el Magistrado sustanciador presentará proyecto de sentencia dentro de los diez (10) días siguientes a haberlo recibido.

5. Y la Corte resolverá dentro de los diez (10) días siguientes a la presentación del Proyecto de Sentencia.

Si el laudo se ajustare a los términos del compromiso o de las cláusulas 
compromisorias y no afectare derechos o facultades reconocidos por la Constitución, por las leyes o por las normas convencionales a cualquiera de las partes, la Corte lo homologará. En caso contrario, lo anulará y dictará la resolución que lo reemplace. Contra estas decisiones de la Corte no habrá recurso alguno.

\section{b. Recurso de homologación en el arbitraje obligatorio}

Regulado en el artículo 819 del Código del Trabajo que se refiere a los laudos que profieran las Juntas de Arbitraje o los Tribunales especiales de arbitramento, cuando el arbitraje fuere de carácter obligatorio (establecido en las cláusulas de los contratos colectivos de trabajo).

1. Será remitido con todos sus antecedentes a la Corte Suprema de Justicia para su homologación a solicitud de una de las partes o de ambas, presentada dentro de los tres (3) días siguientes al de su notificación.

2. La Corte, dentro del término de cinco (5) días, verificará la regularidad del laudo y lo declarará exequible, confiriéndole fuerza de sentencia, si la Junta o Tribunal de arbitramiento no hubiere extralimitado el objeto para el cual se le convocó, o lo anulará en caso contrario.

Si la Corte hallare que no se decidieron algunas de las cuestiones indicadas en el decreto de convocatoria, devolverá el expediente a los árbitros, con el fin de que se pronuncien sobre ellas, señalándoles plazo al efecto, sin perjuicio de que ordene, si lo estima conveniente, la homologación de lo ya decidido.

\section{RECURSOS DE HOMOLOGACIÓN INTERPUESTOS EN HONDURAS}

En la historia de la Corte Suprema de Justicia, a partir de la entrada en vigencia del Código del Trabajo (Decreto No. 189-59), a partir del 23 de Julio de 1959 , en el cual se regula el recurso de homologación contra los laudos arbítrales, solo se han interpuesto dos (02) recursos de homologación: El Primero (Registro de la Corte Suprema 100 - 63) interpuesto el señor HÉCTOR ACOSTA RAMOS, contra el Laudo Arbitral que dictaría el señor Director General del Trabajo con fecha 22 de julio de 1963, en relación a una convocatoria a un congreso extraordinario de delegados del Sindicato de Trabajadores de la Standard Fruit Company (SITRASFRUCO).

El mismo fue declarado sin lugar en virtud de haberse interpuesto directamente 
ante la Corte Suprema de Justicia, en contra de lo establecido en el artículo 817 del Código del Trabajo; y el Segundo fue el recurso de homologación (Registro de la Corte Suprema 723-89), interpuesto por el Abogado EGARDO CÁCERES CASTELLANOS, como apoderado legal del SITRAIMPREMA, respecto al arbitraje voluntario del conflicto colectivo de trabajo suscitado entre el Instituto Nacional de Previsión del Magisterio (IMPREMA) y el Sindicato de Trabajadores de dicho Instituto (SITRAIMPREMA), contra el laudo arbitral de fecha 7 de Julio de 1989; en este conflicto el árbitro fue el ingeniero José Simón Azcona Hoyo, en ese entonces Presidente Constitucional de la República, y es el único recurso de Homologación en el cual existe jurisprudencia, pues la Corte Suprema de Justicia si dictó sentencia, en la que se declaró sin lugar el recurso de Homologación a que se ha hecho referencia y que más adelante estudiaremos.

\section{ANÁLISIS DE LA ÚNICA SENTENCIA RECAÍDA EN UN RECURSO DE HOMOLOGACIÓN EN HONDURAS}

La sentencia de la Corte Suprema de Justicia, se divide en cuatro partes:

La primera es el preámbulo del fallo, que contiene los elementos que se describirán a continuación.

La segunda son los resultados o resumen de antecedentes en las instancias anteriores.

La tercera son los considerandos en la misma donde se exponen las consideraciones de derecho que los magistrados de la Corte Suprema de Justicia estiman son pertinentes al caso.

Y la cuarta es la parte dispositiva o fallo en la que se resuelve el asunto.

\section{SE PROCEDE A CONTINUACIÓN A DESCRIBIR LA ÚNICA SENTENCIA EN MATERIA DE HOMOLOGACIÓN QUE HA DICTADO ESTE SUPREMO TRIBUNAL DEJUSTICIA}

1. Se comienza el preámbulo con la formula "CORTE SUPREMA DE JUSTICIA. Tegucigalpa, MDC., seis de Septiembre de mil novecientos ochenta y nueve. VISTO: Con sus antecedentes el recurso de Homologación interpuesto por el señor EDGARDO CÁCERES CASTELLANOS, mayor de edad, casado, Abogado y de este domicilio con carnet del Colegio Profesional No. 0536, actuando en su condición de apoderado legal del Sindicato de trabajadores 
del Instituto Nacional de Previsión del Magisterio (SITRAIMPREMA), contra el laudo arbitral proferido por el ciudadano Presidente Constitucional de la República. Ingeniero JOSÉ SIMÓN AZCONA HOYO, en su condición de árbitro único en el arbitramiento voluntario a que se sometieron sus representados y el Instituto Nacional de Previsión del Magisterio (IMPREMA), en el conflicto colectivo económico entre las partes.

2. RESULTA: Que constan en autos los siguientes documentos:

a. Memorando del Ministro de Gobernación y Justicia para el señor Presidente de la República de fecha 7 de marzo de 1989 referente al reclamo de la Central General de Trabajadores de Honduras (CTH), sobre conflicto entre IMPREMA Y SITRAIMPREMA (folios 1 y 2).

b. Oficio dirigido al Licenciado JOSÉ CECILIO CASTRO BRANDHS, Secretario Ejecutivo del IMPREMA, de fecha 7 de enero de 1989 suscrita por la Junta Directiva del SITRAIMPREMA (folio 3 y 4).

c. Oficio No. SE-63-89 de fecha 18 de enero de 1989 dirigido por el Secretario Ejecutivo del IMPREMA al ministro de Gobernación y Justicia y representante propietario ante el Directorio del IMPREMA (folios 5 y 6 ).

d. Oficio NO. SE 83-89 de fecha 20 de enero de 1989 con membrete del Instituto Nacional de Previsión del Magisterio, dirigido al Ministerio de Gobernación y Justicia, Abogado Enrique Ortez Colindres, sin firma (folio 7).

e. Fotocopia de una Acta de Compromiso suscrita en esta ciudad el 2 de febrero de 1988 por los representantes del IMPREMA Y SITRAIMPREMA, ante los oficios del Presidente Constitucional de la República, Ingeniero José Simón Azcona Hoyo, el Ministro de Trabajo y Previsión Social Licenciado Alberto Discua Rodríguez.; asistido por el Director General del Trabajo Benjamín Cruz Cárcamo y del Inspector General del Trabajo Licenciado Cesar B. Baquedano Herrera (Folios 8 y 9).

f. Oficio sin número de fecha 17 de enero de 1989 dirigido al señor Presidente de la República Ingeniero José Simón Azcona Hoyo, suscrito por el Secretario General de la C.T.H. Andrés Víctor Artiles (folio 10 y 11).

g. Nota denominado "Acuerdo único", suscrito por el señor Mario Amilcar Quintanilla presidente del Comité Ejecutivo de la FESITRANH en el que se solicita al señor Presidente de la República Ingeniero José Simón Azcona Hoyo para que actué como árbitro en el conflicto obrero patronal que afronta el Sindicato de Trabajadores del Instituto Nacional de Previsión del 
Magisterio (SITRAIMPREMA) de fecha 24 de mayo de 1989. (Folio 12).

h. Oficio No. Sd-061-89 de fecha 31 de mayo de 1989 dirigido al Presidente Constitucional de la República, Ingeniero José Simón Azcona Hoyo, suscrito por el Presidente y Secretario del IMPREMA, en que se nombra al señor Presidente Constitucional de la República como árbitro para que resuelva sobre determinados puntos y adjunten la propuesta presentada al señor del directorio por el COLPROSUMAH, COPEMH, PRICHMA, COPRUMH y la Asociación de Maestros jubilados y pensionados de Honduras (folios 13, 14, y 15).

i. Oficio sin número, de fecha seis de junio de 1989 dirigido al Presidente Constitucional de la República por el Comité Ejecutivo Nacional de la C.T.H. suscrita por los señores Neptali García V. y Erasmo Flores Secretario de actas por ley (folio 16 y 17 ).

j. Oficio No. Pr410-89 de fecha 6 de Junio de 1989 dirigido al Director Ejecutivo del IMPREMA, suscrito por el señor José Azcona Hoyo Presidente Constitucional de la República por el SITRAIMPREMA en que se le comunica aceptar el arbitraje voluntario y señalan los términos a que debe sujetarse el laudo en los aspectos que se consignan y suscrita por los miembros de la junta directiva de la citada organización social (folio 19, 20, $21, y 22)$.

k. Oficio de fecha 9 de junio de 1989 dirigido al Presidente Constitucional de la República con membrete del Instituto de Previsión del Magisterio IMPREMA y sin firma con dos listados adjuntos (folio 25 al 29).

I. El texto de la resolución Arbitral (folio 30 al 35); y a folio 36, el Acuerdo del Poder Ejecutivo No. 144/89 de fecha 19 de junio de 1989 donde se nombra en atención al contenido del numeral octavo de la resolución arbitral, INSPECTOR ESPECIAL al ciudadano Orlando Díaz Núñez, suscrito por el Presidente Constitucional de la República y refrendado por el Ministro del Trabajo y Previsión Social por ley señor Ismael Zapata.

RESULTA: Que con fecha 20 de junio de 1989 compareció ante los oficios del árbitro único el Abogado Edgardo Cáceres Castellanos actuando como apoderado legal del Sindicato de Trabajadores del Instituto Nacional de Previsión del Magisterio IMPPREMA, interponiendo el recurso extraordinario de homologación contra el laudo arbitral proferido con fecha 15 de junio del corriente año, en el arbitramiento voluntario a que se hace referencia (folio 43 y 44) y en fecha 21 de junio aparece la nota de remisión de las diligencias inherentes al arbitraje voluntario del recurso extraordinario de homologación 
interpuesto (folio 45).

RESULTA: Que se nombró Magistrado ponente en las presentes diligencias al abogado Evelio Rodríguez Armijo, quien en su oportunidad informo tener redactado el proyecto de sentencia respectiva, Ordenando este tribunal se dictase o que procediere de conformidad al derecho.

3. CONSIDERANDO: Que el arbitramiento debe ser objeto de un convenio entre las partes interesadas, cuya finalidad es la de someter a la decisión de terceros llamados árbitros, las diferencias que expresamente se señalan en el mismo.

CONSIDERANDO: Que se denomina arbitraje, propiamente dicho a la jurisdicción de terceros llamados árbitros, el sometimiento de las diferencias que expresamente se tengan entre las partes en un conflicto.

CONSIDERANDO: Que el compromiso o sea la cláusula compromisoria a que se refiere el artículo 808 del Código de Trabajo, es la conductio juris para que los árbitros adquieran la autoridad propia de la autoridad judicial respectiva, quedando por consiguiente los árbitros investidos de jurisdicción y competencia para conocer y decidir las controversias que son objeto de arbitramiento, de tal forma y manera que su fallo tiene el mismo valor y la misma fuerza que la ley asigna a las sentencias judiciales.

CONSIDERANDO: Que la cláusula compromisoria deberá hacerse constar siempre por escrito, bien en el contrato individual, en el contrato colectivo en la convención colectiva o en cualquier otro documento otorgado posteriormente, en la cual debe de existir concurrencia de voluntades y coincidencia en cuanto a todos y cada uno de los puntos sometidos a la decisión arbitral.

CONSIDERANDO: Que a falta de cláusula compromisoria previa, el conflicto colectivo no sujeto al arbitramiento obligatorio, se regula por el procedimiento establecido por el capítulo XIII del Código del Trabajo que comprende las etapas de arreglo directo, mediación y conciliación cuyos antecedentes no obran ni constan en los autos del expediente que se conoce.

CONSIDERANDO: Que en el expediente venido a este Tribunal no consta ningún documento previo al conflicto o concluida la etapa de conciliación, que tipifiquen la institución jurídica denominada cláusula compromisoria, pues en las cartas y oficios girados al Presidente Constitucional de la República por los representantes de las partes en discordia que corren a folios trece (13) y diecinueve (19), no existe coincidencia en cuanto a todos y cada uno de los puntos o extremos sometidos a la decisión arbitral. 
CONSIDERANDO: Que la facultad de la Corte en el Recurso de Homologación no se limita a establecer si las disposiciones de la sentencia afectan o no los derechos de las partes protegidos por la Constitución de la República, la ley o la convención para homologarla o anularla. Su emisión es mucho más amplia, examina lo regular del laudo y al hacerlo estudia la naturaleza de conflicto si se han cumplido las etapas de arreglo de conciliación, si el arbitramiento se ha integrado conforme a la ley, si ha funcionado conforme a las normas establecidas y si su sentencia ha sido dictada en tiempo y forma. Como se ve, el control jurisdiccional que la ley concede a la Corte es completo, es por ello que se ha hecho el estudio con los resultados que se hacen constar en las consideraciones que anteceden.

CONSIDERANDO: Que no existiendo clausula compromisoria ni habiéndose concluido ninguna de las etapas establecidas por la ley para llegar a acogerse al arbitramiento voluntario que resuelve el conflicto colectivo de trabajo suscitado entre el Instituto Nacional de Previsión del Magisterio INPREMA, y el Sindicato de Trabajadores de dicho Instituto (SITRAINPREMA) éste surge de hecho por carecer de jurisdiccionalidad para los efectos del recurso homologación.

POR TANTO: La Corte Suprema de Justicia, en nombre del Estado de Honduras, por unanimidad de votos y en aplicación de los artículos 135 y 139 de la Constitución de la República; 1,2,18,77, 491, numeral 3‥, 492 numeral $2^{\circ} ., 3^{\circ} ., y^{\circ} ., 493,396,648,790 ., 791 .$, 792., 793., 794., 795., 803., 806., 807., 808., 809., 817., y 818 del Código del Trabajo.

RESUELVE: DECLARAR SIN LUGAR el Recurso de Homologación de que se ha hecho mérito por las consideraciones que anteceden, y MANDA: Que con certificación de esta resolución se devuelvan a la oficina de su procedencia los antecedentes para los efectos consiguientes- NOTIFIQUESE.

\section{BIBLIOGRAFÍA}

Cáceres Castellano, Edgardo. "Derecho del Trabajo Hondureño" (ensayos, homenajes, y ponencias.. Editorial Sofia, Tegucigalpa, 1992.

Diccionario Jurídico Elemental. Guillermo Cabanellas. Heliasta, Argentina, 1977. Código del Trabajo de Honduras 1959.

Recursos de Homologación presentados ante la corte suprema de justicia, con registros 100-63 y 723-89. 


\section{ANEXOS}

\section{CORTE SUPREMA DE JUSTICIA \\ REPÚBLICA DE HONDURAS, C.A.}

\section{EN CASACIÓN}

$\underline{3^{a} . P I E Z A}$

Recurso de: HOMOLOGACIÓN

Formalizado por el señor:_ HÉCTOR ACOSTA ROMERO

Por el Árbitro:

Director General del Trabajo

De:

En:

No. de Registro R.C.S. de Justicia:

Magistrado Ponente Abogado:

Mes: treinta de julio delaño 1963

\section{SE INTERPONE RECURSO EXTRAORDINARIO DE HOMOLOGACIÓN}

Honorable Corte Suprema de Justicia:

Yo, HÉCTOR ACOSTA ROMERO, mayor de edad, soltero y del vecindario de la ciudad Puerto de la Ceiba, de trámite en esta ciudad, con mi acostumbrado respeto vengo ante esta Honorable Corte Suprema de Justicia a Interponer recurso extraordinario de homologación contra la resolución arbitral emitida por el Director General de Trabajo en la Ciudad de la Ceiba, con fecha 22 de de Julio del corriente año en el expediente que obra en la Sección del Trabajo de dicha ciudad y por lo tanto se resuelve:

1.- Convocatoria a un Congreso Extraordinario de Delegados y demás Representativos del SITRASFRUCO, que deberá inaugurar sus sesiones en la ciudad de la Ceiba el día 31 de julio del año en curso.

2.- Que el acuerdo de convocatoria suscrito conjuntamente por los señores: Héctor Acosta Romero, Modesto Martínez Andrade, Ignacio Meléndez Vallecillo, Salomón Contreras C. y Javier Arguijo Benítez por una parte y Pablo Sequeira Rodríguez, Alejandro Sevilla Cárcamo, José Ramón Raudales, Eduardo Rodríguez Deras, Bartolo Estrada Martínez, Ramón Oseguera Zelaya, y 
Bartolomé Mejía Suazo. Por la otra parte todos afiliados al Sindicato de Trabajadores de la Estándar Fruit Company.

3.- Qué dada la naturaleza de Resolución Arbitral de la presente, si alguno o algunos de los que devienen obligados a suscribirla se negaren a hacerlo, sea dicha convocatoria suscrita por aquellos dispuestos a acatar la Resolución Arbitral, que por otra parte debe ser acatada por todos.

4.- Qué la expresada convocatoria sea hecha el día de hoy (22 de Julio) como acto incontinenti a la notificación de esta Resolución Arbitral y que en la misma se excite a las sub-seccionales y secciónales de línea o puenteras así como a cualquier otro organismo que le corresponda acreditar delegados de conformidad con los estatutos del SITRASFRUCO, para que dé los pasos necesarios a efecto de que no se produzcan contratiempos en nominación de los respectivos delegados.

5.- Que de los fondos que tiene depositados el "SITRASFRUCO" en la sucursal del Banco Atlántida, de esta ciudad se retiren únicamente las cantidades necesarias para los siguientes fines:

a) Las cantidades necesarias para cubrirle los sueldos atrasados y hasta el treinta de junio a los trabajadores que han venido prestando sus servicios en las Oficinas del Sindicato, en cuyo grupo se aclara que no quedan incluidos los Directivos Sindicales de las Directivas apócrifas encabezadas por Acosta Romero y Sequeira Rodríguez. b) Las cantidades para cubrir el alquiler del local que ocupa el Sindicato y los gastos de alumbrado, suscripción de periódicos y programas radiales de publicidad y propaganda, hasta el treinta de junio; c) Las cantidades necesarias para cubrir las cuotas correspondientes a dos pólizas que el Sindicato tiene en el Banco de la Propiedad, por los meses de mayo, junio y julio; d) Las cantidades necesarias para cubrir los gastos de escritorio; e) Las cantidades necesarias para cubrir los viáticos de los Congresales y de los Comisionados.

6.- Que en cuanto concierne al pago del salario a que alegan tener derecho los miembros de las Directivas apócrifas, faltando únicamente diez días para la instalación del Congreso Extraordinario y siendo este aspecto uno de los más controvertidos, sea dicho Congreso el que se pronuncie sobre el particular.- Se aclara que en manera alguna lo resuelto en los párrafos anteriores deba interpretarse como una negociación en razón de criterio, de supuestos derechos.

7.- Para retirar el total que arroja la suma de las cantidades parciales arriba especificadas, se seguirá el siguiente procedimiento: a) Se elaborará un cuadro general del gasto que será autorizado conjuntamente por los doce miembros mencionados en la parte introductoria de esta Resolución.- Los cheques para retirar las cantidades previamente tasadas serán suscritos conjuntamente por los 
señores Héctor Acosta Romero, Javier Arguijo Benítez y Ramón Oseguera Zelaya, a quienes se les atribuye para estos efectos y en forma convencional el carácter de Presidente, Tesorero y Fiscal. b) Si hubiese desacuerdo y parte de los miembros se negaren a suscribir el cuadro general de gastos este deberá ser autorizado por los restantes miembros que se mantengan respetuosos a esta Resolución, pasando copia del citado cuadro a la sección de Inspección de Trabajo de esta localidad.Si autorizando el respectivo cuadro hubiere dificultad para retirar fondos porque aquellos a quienes les corresponde firmar los cheques se negaren a hacerlo. Podrán ser éstos firmados por tres de los miembros de los que permanezcan firmes al acatamiento de esta resolución y que solo para estos efectos adquirirán convencionalmente la calidad de Presidente, Tesorero y Fiscal. Si en cuanto a lo que concierne al movimiento de los fondos a que nos hemos referido se presentare alguna dificultad no regulada o imprevisible, quedan autorizados los que permanezcan firmes en el acatamiento de esta resolución. Para tener por otros medios, que incluyen el compromiso y el préstamo con cargo a la cuenta del Sindicato los valores que sean esencialmente indispensables, para la instalación del Congreso.

8.- Que para los efectos de supervisión del proceso de elección de los delegados al Congreso Extraordinario a reunirse, sean integradas sendas comisiones compuestas por un miembro de cada uno de los grupos nominados anteriormente y el correspondiente inspector del trabajo; que si alguno o alguna de los miembros adoptare la actitud de negarse a integrar tales comisiones, sean estas integradas por miembros de los que han permanecido respetuosos a esta resolución y un inspector del trabajo; en el caso de que algunas secciónales se negaren a acreditar representantes al Congreso, se instale con aquellos delegados que hubieren sido acreditados como tales por las restantes seccionales.

9.-Si una vez instalado el Congreso Extraordinario de delegados previo a la declaración de apertura del mismo que deberá ser hecha por los miembros del sindicato que hayan venido actuando como encargados de los preparativos del Congreso se proceda a la elección de un Directorio Provisional, de entre los Miembros del Propio Congreso, el cual deberá estar integrado por un Presidente, un vicepresidente, un Secretario y un Prosecretario. Que una vez en posesión el Directorio Provisional procede la Asamblea de Delegados, bajo la dirección de dicho directorio a nominar las siguientes comisiones: De Revisión de Credenciales, de Presupuesto, de Finanzas, cuantas otras estimare el Congreso, que fueran necesarias para el logro de todos y cada uno de los objetivos perseguidos. Que en definitiva proceda la Asamblea de Delegados a nominar, la 
junta Directiva Central y los Miembros integrantes del Tribunal de Justicia, Fiscalización y Vigilancia. Se deja en claro lo que constituye una ratificación a uno de los apartados del contenido de los arreglos del diez de los corrientes, que salvo disposición en contrario del Congreso a través de su asamblea, todas y cada una de las personas nominadas en la parte introductoria de esta resolución arbitral, tendrá voz y voto en el seno del mismo, no obstante que concurran sin ostentar la calidad de delegados de Junta Directiva alguna que en lo que concierne a la central no la hay legalmente. Queda asimismo en claro que por las circunstancias anteriormente apuntadas, no se podrá producir derecho al doble voto, y que cuando cualquiera de las personas nominadas concurra al Congreso como Delegado, el derecho al voto será consecuencia de esta representación.

10.-Queda bajo las personas nominadas la responsabilidad la orientación del proceso de elección de la Junta Directiva Central de "SITRASFRUCO", del Comité de Justicia, Fiscalización y Vigilancias y demás aspectos conexos. Ante las autoridades del trabajo realizar todas aquellas gestiones encaminadas al logro del propósito apuntado, y las que el suscrito se permita manifestar, serán inmediatamente atendidas por el Ministerio de Trabajo y Previsión Social, como una cooperación o como una obligación a favor de la solución del Problema.

11.-Que este fallo arbitral sea notificado a las partes, para su conocimiento a través de la sección Inspección del Trabajo de esta ciudad, la que extenderá la Certificación de su contenido a ambas partes. Que quedó en conocimiento de las mismas de que esta resolución por el hecho de su notificación y solo por este hecho se efectué está directamente o mediante cedula fijada en la Tabla de Avisos del citado Despacho. Comienza a surtir efectos cobrando automática vigencia. La presente resolución no fue firmada por el Grupo que encabeza él que habla, por no estar de acuerdo con ella. Para mayor comprensión se acompaña copia simple de la resolución arbitral, para que sea agregada a los autos. EI presente recurso lo interpongo en vista de que al Director General del Trabajo nadie le ha dado facultades de árbitro y en el expediente que obra en la sección de inspección en la Ciudad de la Ceiba no existe ningún documento, ni escrito alguno en el cual las partes que intervienen en este conflicto le hayan dado autoridad de árbitro al señor Director General del Trabajo. Por lo cual su resolución arbitral es ilegal y arbitraria, pues se ha tomado atribuciones que no tiene.

Considero violado el artículo 5 de la Constitución de la República en relación con el artículo 808 del Código de Trabajo. Fundo el presente recurso en los artículos 817, 818 del Código de Trabajo por lo antes expuesto a la honorable 
Corte Suprema de Justicia pido: Admitir el presente recurso extraordinario de homologación ordenando el arrastre de las diligencias originales, para lo cual deberá librarse la respectiva comunicación al señor Jefe de la Sección de Inspección del Trabajo de la Ciudad de la Ceiba, en cuyo poder se encuentran las citadas diligencias que una vez seguidos los tramites de Ley se emita sentencia por el cual se anule la resolución arbitral, emitida por el Director General del Trabajo.

Con fecha 22 de julio del corriente año por ser ilegal, injusta y arbitraria y perjudicar los intereses del Sindicato de Trabajadores de la Estándar Fruit Company, y no haberse sujetado a los procedimientos que establece la Ley, en este caso el Código de Trabajo; y por último que se declare la suspensión de la Ejecución de los Actos que Ordena la resolución arbitral.

Para que me represente en este caso le confiero poder al Licenciado Dionisio Matute Gutiérrez, con domicilio en esta ciudad a quien le otorgo todas las facultades generales del mandato judicial.

Tegucigalpa, M.D.C., 24 de Julio de 1963.

\section{Dionisio Gutiérrez}

Presentada a la fecha a las 3:35 p.m. Doy fe del poder conferido al Licenciado Dionisio Matute Gutiérrez.-Id: No. 2 Folio 39, Libro I, presentado con una copia simple de resolución arbitral.

CORTE SUPREMA DE IUSTICIA .- Tegucigalpa, M.D.C., treinta de julio de mil novecientos sesenta y tres.

Debiendo haberse interpuesto el presente recurso extraordinario de homologación ante el Árbitro que pronunció el Laudo, declararse sin lugar su admisión.- Art. 817 del Código de Trabajo. NOTIFIQUESE.

Héctor Acosta Romero;
$\frac{\text { Modesto Martínez Andrade, }}{\text { Ignacio Meléndez Vallecillo, }}$
$\frac{\text { Salomón Contreras C, y }}{\text { Lavier Arguijo Benítez }}$

\section{RESOLUCIÓN ARBITRAL}

Local de la sección de Inspección del Trabajo. La Ceiba, veintidós de julio de mil 
novecientos sesenta y tres.

El suscrito, Director General del Trabajo:

CONSIDERANDO: Que el día de ayer, domingo veinticinco de los corrientes, tuvo lugar en este mismo local una reunión conjunta de los señores: Héctor Acosta Romero; Modesto Martínez Andrade, Ignacio Meléndez Vallecillo, Salomón Contreras C, y Javier Arguijo Benítez, por una parte y Pablo Sequeira Rodríguez Deraz, Bartolo Estrada Martínez, Ramón Oseguera Zelaya, y Bartolomé Mejía Suazo, por la otra; todos afiliados al Sindicato cuyas elecciones en razón de vicios sustantivos y formales han sido declaradas nulas y sin ningún valor, en resolución de la Dirección General del Trabajo de fecha trece de los corrientes en cuya reunión estuvo presente el suscrito, Director del Trabajo y en la cual se procedió a considerar la mejor forma para proceder la situación imperante en la zona del SITRASFRUCO que en su razón de falta de gobierno amenaza con caer en el campo de la anarquía, que ya ha comenzado a reinar en sus filas.

CONSIDERANDO: Que en dicha sesión de trabajo se dejó establecido tal consta en el texto del Acta de la respectiva audiencia: que como consecuencia de la medida adoptada en forma unilateral por el grupo que encabeza el señor Héctor Acosta Romero, grupo que pretende erigirse en juez y parte al hacer manifestación escrito de desconocimiento a la solución de arreglo que definió el problema de SITRASFRUCO, por acuerdo en las partes en pugna. En sesión y acto solemne que registra el acta de diez de los corrientes, cuyo testimonio se tiene a la vista se ha hecho surgir un nuevo problema que es de suma urgencia la convocatoria e instalación de un Congreso Extraordinario de delegados del SITRASFRUCO, por cuanto es palpable y sostenible que a medida que transcurre el tiempo se alejan más las posibilidades de una mejor y conveniente solución de problema lo que se está traduciendo en desasosiego no solo de parte de los trabajadores que integran el mencionado Sindicato sino que de otros sectores que de alguna medida resultan influidos por la anormalidad de autos que a la actitud multilateral del grupo que encabeza el señor Acosta Romero, no cabe atribuirle ningún valor como para que pueda dar en tierra con el contenido del acuerdo suscrito en día diez de los corrientes y que por virtud de lo expresado, ello no pasa de ser más que una manifestación de hecho que exige encausarla dentro de las normas que informa la naturaleza de los compromisos suscritos por personas capaces y responsables que no han sido considerados moralmente para hacerlo; que el propósito de la reunión no es venir a entablar discusiones. Que 
lejos de dar real solución del problema hagan surgir otras consecuencias negativas dentro de las mejores convenientes que se presume persiguen los que están interesados en tal solución.

CONSIDERANDO: Que interrogados los grupos que encabezan los señores Héctor Acosta Romero y Pablo Sequeira Rodríguez, en forma conjunta previa discusión que tuvieron lugar por separado en el sentido de cuál era la posesión de los mismos frente a una nueva situación de facto originada y sostenida por el grupo precedido por el señor Héctor Acosta Romero, como se ha dicho anteriormente pretende con un convenio que conserva toda su válidez, no sin antes haber presentado dicho convenio, no podría ser dejado sin efecto a voluntad de una de las partes que contribuyeron a su creación, por cuanto su contenido penetrado de la naturaleza de disposiciones cuya aplicación por tratarse de problemas sindicales deba ser efectiva a través de la participación de las autoridades del trabajo en lo que les concierne, fueron constantes, afirmativos al responder que estimaban la mejor forma de encontrarle solución a un nuevo planteamiento la que consiste en que el Director General del Trabajo emita una resolución en el carácter que más se adecua a derecho.

CONSIDERANDO: Que el Director General del Trabajo después de escuchar ambas partes en cuanto a que sea él quien a través de resolución a la mayor brevedad posible.

CONSIDERANDO: Que en la forma que a Derecho procede emplear con más propiedad para recibir la resolución que le ha sido solicitada por ambas partes al Director General del Trabajo deba ser de naturaleza arbitral.

POR TANTO: El suscrito árbitro resuelve como fórmula de resolución el problema se basa en el siguiente planteamiento:

1.- Convocatoria a un Congreso Extraordinario de delegados y demás representantes que inauguraran sus sesiones en la ciudad de La Ceiba, el día treinta y uno de los corrientes, a la hora que indique el acuerdo de convocatoria. 2.- Que el acuerdo de Convocatoria sea suscrito y conjuntamente por el grupo de las personas que han sido nominadas a la parte introductoria de esta resolución arbitral.

3.- Que dada la naturaleza arbitral de la presente si alguna o alguno de los que devienen obligados a suscribirla se negaran a hacerlo sea dicha convocatoria suscrita por aquellos dispuestos a acatar la resolución arbitral que por otra parte debe ser acatada por todos.

4.- Que la expresada convocatoria sea hecha el día de hoy como acto incognito a la notificación de esta resolución arbitral y que en las mismas se excite a las sub 
seccionales y secciones de líneas y punteras, así como cualquier otro organismo que le corresponda acreditar delegados de conformidad con los estatutos, para que de los espacios necesarios a efecto de que no se produzca contratiempos en la nominación de los respectivos delegados.

5.- Que de los fondos que tiene depositados el "SITRASFRUCO" en la sucursal del Banco Atlántida, de esta ciudad se retiren únicamente las cantidades necesarias para los siguientes fines:

a) Las cantidades necesarias para cubrirle los sueldos atrasados y hasta el treinta de junio a los trabajadores que han venido prestando sus servicios en las Oficinas del Sindicato, en cuyo grupo se aclara que no quedan incluidos los Directivos Sindicales de las Directivas apócrifas encabezadas por Acosta Romero y Sequeira Rodríguez. b) Las cantidades para cubrir el alquiler del local que ocupa el Sindicato y los gastos de alumbrado, suscripción de periódicos y programas radiales de publicidad y propaganda, hasta el treinta de junio; c) Las cantidades necearías para cubrir las cuotas correspondientes a dos pólizas que el Sindicato tiene en el Banco de la Propiedad, por los meses de mayo, junio y julio; d) Las cantidades necesarias para cubrir los gastos de escritorio; e) Las cantidades necesarias para cubrir los viáticos de los Congresales y de los Comisionados.

6.- Que en cuanto concierne al pago del salario a que alegan tener derecho los miembros de las Directivas apócrifas, faltando únicamente diez días para la instalación del Congreso Extraordinario y siendo este aspecto uno de los más controvertidos, sea dicho Congreso el que se pronuncie sobre el particular.- Se aclara que en manera alguna lo resuelto en los párrafos anteriores deba interpretarse como una negociación en razón de criterio, de supuestos derechos. 7.- Para retirar el total que arroja la suma de las cantidades parciales arriba especificadas, se seguirá el siguiente procedimiento: a) Se elaborará un cuadro general del gasto que será autorizado conjuntamente por los doce miembros mencionados en la parte introductoria de esta Resolución.- Los cheques parar retirar las cantidades previamente tasadas serán suscritas conjuntamente por los señores Héctor Acosta Romero, Javier Arguijo Benítez y Ramón Oseguera Zelaya, a quienes se les atribuye para estos efectos y en forma convencional el carácter de Presidente, Tesorero y Fiscal. b) Si hubiese desacuerdo y parte de los miembros se negaren a suscribir el cuadro general de gastos este deberá ser autorizado por los restantes miembros que se mantengan respetuosos a esta Resolución, pasando copia del citado cuadro a la sección de Inspección de Trabajo de esta localidad.- Si autorizando el respectivo cuadro hubiere dificultad 
para retirar fondos porque aquellos a quienes les corresponde firmar los cheques se negaren a hacerlo. Podrán ser éstos firmados por tres de los miembros de los que permanezcan firmes al acatamiento de esta resolución y que solo para estos efectos adquirirán convencionalmente la calidad de Presidente, Tesorero y Fiscal. Si en cuanto a lo que concierne al movimiento de los fondos a que nos hemos referido se presentare alguna dificultad no regulada o imprevisible, quedan autorizados los que permanezcan firmes en el acatamiento de esta resolución. Para tener por otros medios, que incluyen el compromiso y el préstamo con cargo a la cuenta del Sindicato los valores que sean esencialmente indispensables, para la instalación del Congreso.

8.- Que para los efectos de supervisión del proceso de elección de los delegados al congreso extraordinario a reunirse, sean integradas sendas comisiones compuesta por un miembro de cada uno de los grupos nominados anteriormente y el correspondiente inspector del trabajo; que si alguno o alguna de los miembros adoptare la actitud de negarse a integrar tales comisiones, sean estas integradas por miembros que han permanecido respetuosos a esta resolución y un inspector del trabajo; en el caso de que algunas secciónales se negaren a acreditar representantes al congreso, se instale con aquellos delegados que hubieren sido acreditados como tales por las restantes seccionales.

9.- Si una vez instalado el Congreso extraordinario de delegados previo a la declaración de apertura del mismo que deberá ser hecha por los miembros del sindicato que hayan venido actuando como encargados de los preparativos del Congreso se proceda a la elección de un Directorio Provisional, de entre los miembros del propio Congreso, el cual deberá estar integrado por un Presidente, un vicepresidente, un Secretario y un Prosecretario. Que una vez en posesión el Directorio Provisional proceda a la Asamblea de Delegados, bajo la dirección de dicho directorio a nominar las siguientes comisiones: De Revisión de Credenciales, de Presupuesto, de Finanzas, cuantas otras estimare el Congreso, que fueran necesarias para el logro de todos y cada uno de los objetivos perseguidos. Que en definitiva proceda la Asamblea de Delegados a nominar, La junta Directiva Central y los Miembros integrantes del Tribunal de Justicia, Fiscalización y Vigilancia. Se deja en claro lo que constituye una ratificación a uno de los apartados del contenido de los arreglos del diez de los corrientes, que salvo disposición en contrario del Congreso a través de su asamblea, todas y cada una de las personas nominadas en la parte introductoria de esta resolución arbitral, tendrá voz y voto en el seno del mismo, no obstante que concurran sin 
ostentar la calidad de delegados de Junta Directiva alguna que en .lo que concierne a la central no la hay legalmente. Queda asimismo en claro que por las circunstancias anteriormente apuntadas, no se podrá producir derecho al doble voto, y que cuando cualquiera de las personas nominadas concurra al Congreso como Delegado, el derecho al voto será consecuencia de esta representación.

10.- Queda bajo las personas nominadas la responsabilidad la orientación del proceso de elección de la Junta Directiva Central de "SITRASFRUCO", del Comité de Justicia, Fiscalización y Vigilancias y demás aspectos conexos.

Ante las autoridades del trabajo realizar todas aquellas gestiones encaminadas al logro del propósito apuntado, y las que el suscrito se permita manifestar, serán inmediatamente atendidas por el Ministerio de Trabajo y Previsión Social, como una cooperación o como una obligación a favor de la solución del Problema.

11.- Que este fallo arbitral sea notificado a las partes, para su conocimiento a través de la sección Inspección del Trabajo de esta ciudad, la que extenderá la Certificación de su contenido a ambas partes. Que quedó en conocimiento de las mismas de que esta resolución por el hecho de su notificación y solo por este hecho se efectué está directamente o mediante cedula fijada en la Tabla Aviso del citado Despacho. Comienza a surtir efectos cobrando automática vigencia.

\section{Armando Madariaga Muñoz}

El veintidós de los corrientes siendo las cinco de la tarde notifique el contenido de la resolución que antecede a los señores Héctor Acosta Romero, Modesto Martínez, Andrade, Ignacio Meléndez Vallecillo, Salomón Contreras, y Javier Arguijo Benítez, por una parte y Pablo Sequeira Rodríguez, Alejandro Sevilla Cárcamo, José Romero Raudales, Eduardo Rodríguez Darás, Bartolo Estrada Martínez, Ramón Oseguera Zelaya y Bartolomé Mejía Suazo por la otra. El grupo encabezado por Acosta Romero dijo en común que han quedado debidamente enterados del texto de la Resolución que en este acto se les ha notificado y que no estando de acuerdo, así lo expresan, no firmando por manifestarlo, no querer hacerlo, el grupo encabezado por Pablo Sequeira Rodríguez dijo: Que al enterarse del contenido de la Resolución Arbitral, quedan entendidos y de acuerdo con la misma firmado para constancia. 


\section{CORTE SUPREMA DE JUSTICIA}

República de Honduras

\section{SIN LUGAR \\ RECURSO DE HOMOLOGACIÓN}

723-89

INTERPUESTO POR EL ABOGADO EDGARDO CÁCERES CASTELLANOS COMO APODERADO LEGAL DEL SITRAINPREMA, RESPECTO AL ARBITRAJE VOLUNTARIO DEL CONFLICTO COLECTIVO DEL TRABAJO SUSCITADO ENTRE EL INSTITUTO NACIONAL DE PREVISIÓN DEL MAGISTERIO (INPREMA) Y EL SINDICATO DE TRABAJADORES DE DICHO INSTITUTO (SITRAINPREMA).

\section{3-89 \\ RECURSO DE HOMOLOGACIÓN}

Contra Laudo Laboral

\section{TEGUCIGALPA, M.D.C., 20 DE SEPTIEMBRE DE 1989}

Tegucigalpa, M.D.C., 21, de junio, 1989

Honorable Corte Suprema de Justicia

Para efectos de Ley correspondientes en esta fecha, remito a ese Tribunal de Justicia, las diligencias inherentes al Arbitraje voluntario del conflicto Colectivo de Trabajo suscitado entre el Instituto Nacional de Previsión del Magisterio (INPREMA), y el Sindicato de Trabajadores de dicho Instituto (SITRAINPREMA), y recurso extraordinario de Homologación, interpuesto por el Abogado Edgardo Cáceres Castellanos como Apoderado Legal del (SITRAINPREMA, constando de 45 folios útiles.

\section{JOSÉ AZCONA H.}

ARBITRO

Recibido en veintiuno de junio de mil novecientos ochenta y nueve a las tres con treinta minutos de la tarde, con una pieza constante de cuarenta de cuatro (44) folio y copia simple del escrito del recurso de homologación.

Ricardo Bogran H. 
CORTE SUPREMA DE JUSTICIA.- Tegucigalpa, MD.C., veintidós de Agosto de mil novecientos ochenta y nueve.

Habiéndose recibido por éste Supremo Tribunal de Justicia las diligencias inherentes al Arbitraje voluntario del Conflicto Colectivo de Trabajo suscitado entre el instituto Nacional de Previsión del Magisterio (INPREMA), y el Sindicato de Trabajadores del dicho Instituto (SITRAINPREMA), y el recurso extraordinario de Homologación, interpuesto por el Abogado Edgardo Cáceres Castellanos como Apoderado legal del (SITRAINPREMA), pasen las diligencias al Magistrado Ponente Abogado EVELIO RODRÍGUEZ ARMIJO para que dentro del término de diez días formule el Proyecto de sentencia respectivo.- Artículo 818 del Código del Trabajo.- NOTIFÍQUESE.

\section{Corte Suprema de Justicia \\ Sello \\ Secretaria \\ Corte Suprema de Justicia}

En la misma fecha notificado el Magistrado EVELIO RODRÍGUEZ ARMIJO, de la providencia que antecede, firma entendido

\section{Firmar}

Corte Suprema de Justicia

\section{INFORME}

El suscrito, Magistrado de la Corte Suprema de Justicia, habiendo sido designado Magistrado Ponente en las presente diligencias, informa al Tribunal que tiene formulado el proyecto de sentencia respectivo.

Tegucigalpa, M.D.C., 30 de Agosto de 1989.

\section{Evelio Rodríguez Armijo}

\section{Firma}

CORTE SUPREMA DE JUSTICIA.- Tegucigalpa, M.D.C., uno de Septiembre de mil novecientos ochenta y nueve.

Visto el informe que antecede, díctese la sentencia respectiva dentro del término legal.- Artículo 818 del Código de Trabajo.- NOTIFÍQUESE. 


\author{
José Armando Ávila \\ Firma \\ Corte Suprema de Justicia \\ Héctor Acosta Romero \\ Modesto Martínez Andrade \\ Ignacio Meléndez Vallecillo \\ Salomón Contreras C. \\ Javier Arguijo Benítez \\ Pablo Sequeira Rodríguez Deraz \\ Bartolo Estrada Martínez \\ Ramón Oseguera Zelaya \\ Bartolomé Mejía Suazo \\ Jose A. Sevilla \\ Firma y Sello \\ Secretaria General \\ Corte Suprema de Justicia
}

En cuatro de septiembre de mil novecientos ochenta y nueve, siendo las dos de la tarde, notifiqué el auto que antecede al Abogado Edgardo Cáceres Castellanos, por medio de cédula de notificación que fije en la Tabla de Avisos de este Tribunal.

\author{
José A. Sevilla \\ Sevilla \\ Firma y Sello \\ Secretaria General \\ Corte Suprema de Justicia
}

CORTE SUPREMA DE JUSTICIA.- Tegucigalpa, Municipio del Distrito Central, seis de septiembre de mil novecientos ochenta y nueve.

VISTO: Con sus antecedentes el recurso de Homologación Interpuesto por el señor EDGARDO CACERES CASTELLANOS, mayor de edad, casado, Abogado y de este domicilio con carnet del Colegio de Profesional No. 0536, actuando en su condición de apoderado legal del Sindicato de Trabajadores del Instituto Nacional de Previsión del Magisterio (SITRAINPREMA), contra el Laudo Arbitral proferido por el ciudadano Presidente Constitucional de la República, Ingeniero JOSE 
SIMÓN AZCONA HOYO, en su condición de Arbitro Único en el Arbitramiento Voluntario a que se sometieron sus representados y el Instituto Nacional de Previsión del Magisterio (INPREMA), en el conflicto colectivo económico surgido entre las partes.

RESULTA: Que constan en autos los siguientes documentos: a) Memorándum de Ministro de Gobernación y Justicia para el señor Presidente de la República de fecha 7 de marzo de 1989 referente al reclamo de la Central General de Trabajadores de Honduras ( C.T.H. ) sobre el conflicto entre INPREMA Y SITRAINPREMA (Folio 1 y 2). b) Oficio dirigido al Licenciado JOSÉ CECILIO CASTRO BRANDHS, Secretario Ejecutivo del INPREMA de fecha 7 de enero de 1989, suscrito por la Junta Directiva del SITRAINPREMA (Folio 3 y 4). c) Oficio No.SE-63-89 de fecha 18 de enero de 1989 dirigido por el Secretario Ejecutivo del INPREMA al Ministro de Gobernación y Justicia y Representante propietario ante el Directorio del INPREMA (Folio 5 y 6). d) Oficio No._SE83-89 de fecha 20 de enero de 1989 con membrete del Instituto de Previsión del Magisterio, dirigido al Ministro de Gobernación y Justicia Abogado Enrique Ortez Colindres, sin firma (Folio 7). e) Fotocopia de una acta de compromiso suscrita en esta ciudad el 2 de febrero de 1988 por los representantes del INPREMA Y SITRAINPREMA, ante Ios oficios del Presidente Constitucional de la República, Ingeniero José Simón Azcona Hoyo, el Ministro de Trabajo y Previsión Social Licenciado Alberto Discua Rodríguez; asistido por el Director General de Trabajo Benjamín Cruz Cárcamo y del Inspector General del Trabajo Licenciado Cesar B. Baquedano Herrera (folio 8 y 9). f) Oficio sin número de fecha 17 de enero de 1989 dirigido al señor Presidente de la República Ingeniero José Simón Azcona Hoyo, suscrito por el Secretario General de la C.T.H. Andrés Víctor Artiles (folio 10 y 11). g) Nota denominada "ACUERDO ÚNICO", SUSCRITO POR EL SEÑOR Mario Amílcar Quintanilla Presidente del Comité Ejecutivo de la FESITRANH en el que se solicita al señor Presidente de la República Ingeniero José Simón Azcona Hoyo para que actúe como Arbitro en el conflicto Obrero Patronal que afronta el Sindicato de Trabajadores del Instituto Nacional de Previsión del Magisterio (SITRAINPREMA) de fecha 24 de Mayo de 1989. (folio 12) h) Oficio No. SD-061-89 de fecha 31 de mayo de 1989 dirigido al Presidente Constitucional de la República Ing. José Simón Azcona Hoyo, suscrito por el Presente y Secretario del INPREMA, en que se nombre al señor Presidente Constitucional de la República como Arbitro para que resuelva sobre determinados puntos y adjuntan la propuesta presentada al señor del Directorio por el COLPROSUMAH, COPEMH, PRICMAH, COPRUMH y la Asociación de Maestros Jubilados y Pensionados de Honduras (folio 13, 14, y 15). I) 
Oficio sin número de fecha 6 de junio de 1989 dirigido al señor presidente Constitucional de la República por el Comité Ejecutivo Nacional de la C.T.H. SUSCRITA POR LOS SEÑORES Neptali García V., presidente por Ley y Erasmo Flores, Secretario de Actas por Ley (folio 16 y 17). J) Oficio No. PR410/89 de fecha 6 de junio de 1989, dirigido al Director Ejecutivo del INPREMA suscrito por el señor José Simón Azcona Hoyo, Presidente Constitucional de la República solicitando informe (folio 18), k) Oficio del 7 de julio de 1989 dirigido al Presidente Constitucional de la República por el SITRAINPREMA en que se le comunica aceptar el Arbitraje voluntario y señalan los términos a que debe sujetarse el laudo en los aspectos que se consignan y suscrito por los Miembros de la Junta Directiva de la citada Organización Sindical. (folio 19, 20,21 y 22).- I) Oficio de fecha 9 de junio de 1989, dirigido al Presidente Constitucional de la República, con el membrete del Instituto de Previsión del Magisterio y sin firma con dos listados adjuntos (folio 25 al 29). m) El texto de la resolución arbitral (folio 30 al 35) y a folio 36 del Acuerdo del Poder Ejecutivo No 144-8 de fecha 19 de junio de 1989 donde se nombra en atención el contenido del numeral octavo de la resolución arbitral. INSPECTOR ESPECIAL, al ciudadano Orlando Díaz Núñez, suscrito por el Presidente Constitucional de la República, y refrendado por el Ministerio de Trabajo y Previsión Social por Ley, señor Ismael Zapata Rosa.

RESULTA: Que con fecha 20 de Junio de 1989, compareció ante los oficios del árbitro único el Abogado EDGARDO CÁCERES CASTELLANOS, actuando como apoderado Legal del Sindicato de Trabajadores del Instituto Nacional de Previsión del Magisterio interponiendo el Recurso Extraordinario de Homologación, contra el Laudo Arbitral proferido con fecha 15 de junio del corriente año, en arbitramiento voluntario a que se hace referencia (folio 43 y 44). Y con fecha 21 de junio aparece la nota de remisión de las diligencias inherentes al arbitraje voluntario y al Recurso Extraordinario de Homologación interpuesto (folio 45).

RESULTA: Que se nombró magistrado oponente en las presente diligencias al Abogado Evelio Rodríguez Armijo, quien en su oportunidad informó tener redactado el Proyecto de Sentencia respectiva; ordenando este Tribunal se dictase lo que procediese de conformidad a Derecho.

CONSIDERANDO: Que el arbitramento debe ser objeto de un convenio entre las partes interesadas cuya finalidad es la de someter a la decisión de terceros llamados árbitros, las diferencias que expresamente se señalan en el mismo.

CONSIDERANDO: Que se denomina arbitraje propiamente dicho la jurisdicción que en virtud del compromiso o sea cláusula compromisoria a que se refiere el artículo 808 del Código del Trabajo es la conducción jurídica para que los árbitros 
adquieran la atribución propia de la autoridad judicial respectiva, creando por consiguiente los árbitros investidos de jurisdicción y competencia para conocer y decidir las controversias que son objeto de arbitramiento en tal forma y manera que su fallo tiene el mismo valor y la misma fuerza que la Ley asigna a la sentencia judicial.

CONSIDERANDO: Que la cláusula compromisoria deberá hacer constar siempre por escrito, bien en el contrato individual, en el Contrato Colectivo en la Convención Colectiva o cualquier otro documento otorgado posteriormente en la cual deba existir concurrencia de voluntades y coincidencia en cuanto a todo y cada uno de los puntos sometidos a la decisión arbitral.

CONSIDERANDO: Que a falta de cláusula compromisoria previa en el conflicto colectivo no sujeto al arbitramento obligatorio, se regula por el procedimiento establecido en el Capítulo XIII, del Código del Trabajo, que comprende la etapas de arreglo indirecto, medicación y conciliación cuyos antecedentes no obran ni constan en los autos del Expediente que se conoce.

CONSIDERANDO: Que en el expediente venido a este Tribunal no consta ningún documento previo al conflicto o concluida la etapa de conciliación, que tipifique la Institución Jurídica denominada Cláusula Compromisoria pues en las cartas u oficios girados al Presidente Constitucional de la República por los representantes de las partes en discordia que corre en el folio trece (13) y diecinueve (19), no existe coincidencia en cuanto a todos y cada uno de los puntos o extremos sometidos a la decisión arbitral.

CONSIDERANDO: Que la facultad de la Corte en el Recurso de Homologación, no se limita a establecer si las disposiciones de la sentencia afectan o no los derechos de las partes protegidos por la Constitución de la República, la Ley de la convención para homologarla o anularla su misión es mucho más amplia, examina lo regular del Laudo y al hacerlo estudia la naturaleza del conflicto, si se han cumplido las etapas de arreglo directo, de conciliación y el arbitramento se ha integrado conforme a la ley, si ha funcionado conforme a las normas establecidas y si su sentencia ha sido dictada en tiempo y forma. Como se ve, el control jurisdiccional que la ley le concede a la Corte es completo; es por ello que se ha hecho el estudio con los resultados que se hacen constar en las consideraciones que anteceden.

CONSIDERANDO: Que no existiendo Cláusula Compromisoria ni habiéndose concluido ninguna de las etapas establecidas por la Ley para llegar a acogerse al arbitramiento voluntario que resuelve el conflicto colectivo de trabajo suscitado entre el Instituto Nacional de Previsión del Magisterio (INPREMA) y el Sindicato 
de Trabajadores de dicho Instituto (SITRAINPREMA), este surge de hecho por carecer de jurisdiccionalidad para los efectos del Recurso de Homologación.

POR TANTO: La Corte Suprema de Justicia, en nombre del Estado de Honduras, por unanimidad de votos y en aplicación de los artículos 135, 139 de la Constitución de la República; 1,2, 18, 77, 491, numeral 3º, 492 Numeral 2. Y 4º, 396, 648, 790,791, 792,793, 794, 795, 803, 806, 807, 808, 809,817, y 818 del Código del Trabajo, RESUELVE: DECLARAR SIN LUGAR el recurso de Homologación de que se ha hecho merito por las consideraciones que anteceden, y MANDA: Que con Certificación de esta resolución se devuelvan a la oficina de su procedencia los antecedentes para los efectos consiguientes NOTIFIQUESE.

Mauricio Díaz Valle

Juez

Firma y Sello

Corte Suprema de Justicia

Pasan las Firmas

Ignacio Meléndez Vallecillo
Salomón Contreras C
Javier Aguijo Benítez
Pablo Sequeira Rodríguez Deraz,
Bartolo Estrada Martínez,
Ramón Oseguera Zelaya
Bartolomé Mejía Suazo
Héctor Rodríguez
Ramón Oseguera
Mauricio Ricardo Díaz
Juez
Firma y Sello
Corte Suprema de Justicia

En día doce del mes de septiembre de mil novecientos ochenta y nueve, siendo las nueve de la mañana con treinta y seis minutos (9:36 a.m.) notificado el apoderado Edgardo Cáceres Castellanos, de la sentencia que antecede, por este acto interpone el Recurso de Reposición, por no haber conformidad dictada conforme a derecho, Firmado por conforme.

\section{Edgardo Cáceres Castellanos}

CORTE SUPREMA DE JUSTICIA.- Tegucigalpa, M.D.C., veinte de septiembre de mi 
novecientos ochenta y nueve.-

Sin lugar por improcedente el recurso de reposición interpuesto por el Abogado Edgardo Cáceres Castellanas. Artículo 818 párrafo segundo del Código de Trabajo.NOTIFIQUESE.-

\author{
Ignacio Meléndez Vallecillo \\ Salomón Contreras C \\ Javier Aguijo Benítez \\ Pablo Sequeira Rodríguez Deraz \\ Bartolo Estrada Martínez, \\ Ramón Oseguera Zelaya \\ Pasan las Firmas \\ Bartolomé Mejía Suazo \\ Héctor Rodríguez \\ Ramón Oseguera
}

En veintidós del mes de octubre de mil novecientos ochenta y nueve, notifíquese el Abogado apoderado Edgardo Cáceres Castellanos del auto que antecede, con el fin cumplido.

Evelio Rodríguez Armijo 